\title{
Therapeutics
}

\section{Review: cardioselective $\beta$, blockers given for 3 days to 4 weeks do not reduce respiratory function in reactive airway disease}

Salpeter SR, Ormiston TM, Salpeter EE. Cardioselective beta-blockers in patients with reactive airway disease: a meta-analysis. Ann Intern Med 2002;137:715-25.

QUESTIONS: In patients with reactive airway disease, what is the effect of cardioselective $\beta_{1}$ blockers on respiratory function? In these patients, how does treatment with $\beta_{1}$ blockers affect response to $\beta_{2}$ agonists?

\section{Data sources}

Studies were identified by searching Medline, EMBASE/ Excerpta Medica, and CINAHL (all between 1966 and May 2001), and by scanning bibliographies of relevant studies and reviews.

\section{Study selection}

Studies in any language were selected if they were randomised, blinded, placebo controlled trials that assessed the effects of intravenous or oral cardioselective $\beta_{1}$ blockers, given as a single dose or as continued treatment lasting $\geq 3$ days, on airway function $\left(\mathrm{FEV}_{1}\right.$ or symptoms) in patients with reactive airway disease (defined as asthma or chronic obstructive pulmonary disease with a reversible obstructive component).

\section{Data extraction}

Data were extracted on study quality, study design, patient characteristics, interventions, comparison groups, and outcomes (change in $\mathrm{FEV}_{1} ; \mathrm{FEV}_{1}$ response to $\beta_{2}$ agonists given after study drug or placebo; symptoms reported, such as wheezing, dyspnoea, or exacerbation of asthma; and, for trials of continued treatment, weekly use of inhaled short acting $\beta_{2}$ agonists).

\section{Main results}

19 crossover studies on single dose treatment $(n=240$, mean age $40 \mathrm{y}, 79 \%$ men) were included; $\beta_{1}$ blockers assessed were atenolol, metoprolol, bisoprolol, practolol, celiprolol, acebutolol, and xamoterol. Compared with placebo, single doses of cardioselective $\beta_{1}$ blockers reduced $\mathrm{FEV}_{1}$, and increased $\mathrm{FEV}_{1}$ after a $\beta_{2}$ agonist was given (table), with no increase in respiratory symptoms.

10 crossover studies on continued treatment $(n=141$, mean age 51 y, 77\% men) were included. Compared with placebo, continued treatment with cardioselective $\beta_{1}$ blockers did not differ from placebo for $\mathrm{FEV}_{1}$ response (table), respiratory symptoms, or incidence of inhaler use. However, cardioselective $\beta_{1}$ blockers did increase $\mathrm{FEV}_{1}$ more than placebo did after a $\beta_{2}$ agonist was given (table).

\section{Conclusions}

In patients with reactive airway disease, single doses of cardioselective $\beta_{1}$ blockers reduced $\mathrm{FEV}_{1}$ but increased $\mathrm{FEV}_{1}$ after $\beta_{2}$ agonist was given, with no increase in respiratory symptoms. Continued treatment with cardioselective $\beta_{1}$ blockers dose not reduce respiratory function and increases $\mathrm{FEV}_{1}$ response to $\beta_{2}$ agonists.

Source of funding: no external funding.

For correspondence: Dr S Salpeter, Santa Clara Valley Medical Center, San Jose, California, USA. Shelley.salpeter@ hhs.cosanta-clara.ca.us

\begin{tabular}{|c|c|c|c|}
\hline Type of treatment & $\begin{array}{l}\text { Outcomes }\left(\beta_{1}\right. \\
\text { blocker } v \text { placebo) }\end{array}$ & Follow up & WMD (95\% Cl) \\
\hline \multirow[t]{2}{*}{$\begin{array}{l}\text { Single dose of } \beta_{1} \\
\text { blocker }\end{array}$} & Change in $\mathrm{FEV}_{1}$ & $1-6$ hours & $-7.46 \%(-9.32$ to -5.59$)$ \\
\hline & $\begin{array}{l}\mathrm{FEV}_{1} \text { response to } \beta_{2} \\
\text { agonist }\end{array}$ & $1-6$ hours & $4.63 \%(2.47$ to 6.78$)$ \\
\hline \multirow[t]{2}{*}{$\begin{array}{l}\text { Continued treatment } \\
\text { with } \beta_{1} \text { blocker }\end{array}$} & Change in $\mathrm{FEV}_{1}$ & 3 days to 4 weeks & $-0.42 \%(-3.74$ to 2.91$) \dagger$ \\
\hline & $\begin{array}{l}\text { FEV } 1 \text { response to } \beta_{2} \\
\text { agonist }\end{array}$ & 3 days to 4 weeks & $8.74 \%(1.96$ to 15.52$)$ \\
\hline
\end{tabular}

*WMD = weighted mean difference. $\mathrm{Cl}$ defined in glossary

†Not statistically significant.

\section{COMMENTARY}

$\beta_{1}$ blockers have become the standard of care for a wide variety of cardiovascular disorders. Despite their widespread use, many physicians worry about potential adverse reactions in patients with reactive airway disease. Cardioselective $\beta_{1}$ blockers are $>20$ times more selective for the $\beta_{1}$ than $\beta_{2}$ receptors and should carry less risk of bronchoconstriction in reactive airway disease.

The meta analysis by Salpeter et al lends further support to the position that cardioselective $\beta_{1}$ blockers do not cause clinically significant interactions in patients with mild to moderate reactive airway disease. Although a small asymptomatic reduction in FEV occurred after a single dose of cardioselective $\beta_{1}$ blocker compared with placebo, this initial effect did not persist with continued treatment. In addition, $\mathrm{FEV}_{1}$ increased in response to $\beta_{2}$ agonist administration, with short and long term use of cardioselective $\beta_{1}$ blockers.

Several challenges are notable with this meta analysis, some of which may have been unavoidable given the nature of the study. The included patients had only mild to moderate airway obstruction and no recent asthma exacerbations. Because only previously published studies were included, a selection bias may have existed.

This meta analysis lends additional weight to the argument that use of cardioselective $\beta_{1}$ blockers in reactive airway disease is without clinically significant interactions. Although many of the studies in the continuing treatment group had a relatively short duration, the results would suggest that cardioselective $\beta_{1}$ blockers may be safe for long term use. Agents such as metoprolol and atenolol should be the first agents considered. ${ }^{1}$ In contrast to non-cardioselective agents, the effects of cardioselective agents are believed to be easier to reverse. Safety in acute exacerbations remains to be established; if used, a short acting agent such as esmolol should be considered.

Given their mortality benefit in numerous conditions, it is our recommendation that the use of cardioselective $\beta_{1}$ blockers not be restricted in patients with mild to moderate reactive airway disease.

J Britt Jura, MD

Amy R Blanchard, MD

Medical College of Georgia, Augusta, Georgia, USA

1 Tafreshi MJ, Weinacker AB. Beta-adrenergic-blocking agents in bronchospastic diseases: a therapeutic dilemma. Pharmacotherapy 1999;19:974-8. 